\title{
Appropriateness of bone density measurement in Switzerland: a cross-sectional study
}

\author{
Stefan Zechmann ${ }^{1 *}$ (D), Nathalie Scherz ${ }^{1}$, Oliver Reich², Beat Brüngger ${ }^{2}$, Oliver Senn¹, Thomas Rosemann ${ }^{1}$ \\ and Stefan Neuner-Jehle ${ }^{1}$
}

\begin{abstract}
Background: According to the $\mathrm{WHO}$, osteoporosis is one of the most important non- communicable diseases worldwide. Different screening procedures are controversially discussed, especially concerning the concomitant issues of overdiagnosis and harm caused by inappropriate Dual X-ray Absorptiometry (DXA). The aim of this study was to evaluate the frequency and appropriateness of DXA as screening measure in Switzerland considering individual risk factors and to evaluate covariates independently associated with potentially inappropriate DXA screening.

Methods: Retrospective cross-sectional study using insurance claim data of 2013. Among all patients with DXA screening, women $<65$ and men $<70$ years without osteoporosis or risk factors for osteoporosis were defined as receiving potentially inappropriate DXA. Statistics included descriptive measures and multivariable regressions to estimate associations of relevant covariates with potentially inappropriate DXA screening.

Results: Of 1,131,092 patients, 552,973 were eligible. Among those 2637 of 10,000 (26.4\%) underwent potentially inappropriate DXA screening. Female sex (Odds ratio 6.47, Cl 6.41-6.54) and higher age showed the strongest association with any DXA screening.

Female gender (Odds ratio 1.84, Cl 1.49-2.26) and an income among the highest 5\% (Odds ratio 1.40, Cl 1.01-1.98) were significantly positively associated with potentially inappropriate DXA screening, number of chronic conditions (Odds ratio 0.67, Cl 0.65-0.70) and living in the central region of Switzerland (Odds ratio 0.67, Cl 0.48-0.95) negatively.

Conclusion: One out of four DXAs for screening purpose is potentially inappropriate. Stakeholders of osteoporosis screening campaigns should focus on providing more detailed information on appropriateness of DXA screening indications (e.g. age thresholds) in order to avoid DXA overuse.
\end{abstract}

Keywords: Appropriateness, Bone density measurement, DXA, Screening, Osteoporosis, Switzerland

\section{Background}

According to the WHO osteoporosis is one of the most important non-communicable diseases worldwide [1] with a high burden of disease [2-5]. In Switzerland, one out of three women at the age of 85 is at risk for an osteoporotic fracture within ten years [6]. Efficient drugs, which are able to prevent osteoporotic fractures, are available [7-9]. Thus

\footnotetext{
*Correspondence: stefan.zechmann@usz.ch

${ }^{1}$ Institute of Primary Care, University of Zurich, Pestalozzistrasse 24, 8091

Zurich, Switzerland

Full list of author information is available at the end of the article
}

identifying patients likely to benefit from such a therapy is of crucial importance. Besides risk calculators based on individual behavior characteristics $[10,11]$, the standard screening method is Dual X-ray Absorptiometry (DXA) [12]. Its evidence is controversially discussed at present, especially concerning the issues of overdiagnosis and harm resulting from inappropriate DXA screening [13-18]: DXA as a single procedure does not harm patients directly, as the amount of radiation applied is almost negligible. Nevertheless harmful effects of radiation can sum up. The real harm of inappropriate DXA consists in potential additional 
diagnostic procedures (e.g. repeated DXA's) as well as concomitant treatment due to diagnostically significant but clinically irrelevant DXA results. DXA measurements are inherently uncertain in relation to fracture risk prediction [19]. If treatment is initiated based on DXA results alone, e.g. in asymptomatic persons regardless of risk factors, it is potentially inappropriate and can cause potentially severe side effects as well as avoidable costs.

Current knowledge on the use of DXA screening in Switzerland is scarce. Therefore, the aim of this study was to evaluate the frequency and appropriateness of DXA as a screening measure in Switzerland, considering individual risk factors, and to evaluate covariates independently associated with potentially inappropriate DXA screening.

\section{Methods}

\section{Study design and setting}

Retrospective cross-sectional analysis using insurance claims data from the largest insurance company in
Switzerland (Helsana). Data covered in- and outpatient health care in Switzerland, where all residents are have mandatory health insurance provided by private health insurance companies (details on various insurance models see below). The study population was extracted from a dataset of 1,131,092 patients across Switzerland, representing a sample of approximately $14 \%$ of the Swiss population (see Fig. 1).

\section{Subjects and data collection Inclusion criteria}

All health claims submitted to Helsana for reimbursement of health care provided between January 1st and December 31st 2013 were considered and included following codes:

a. Outpatient setting: Outpatient care fees-for-services positions (Tarmed) and Anatomical Therapeutic Chemical (ATC) Classification System for drugs.

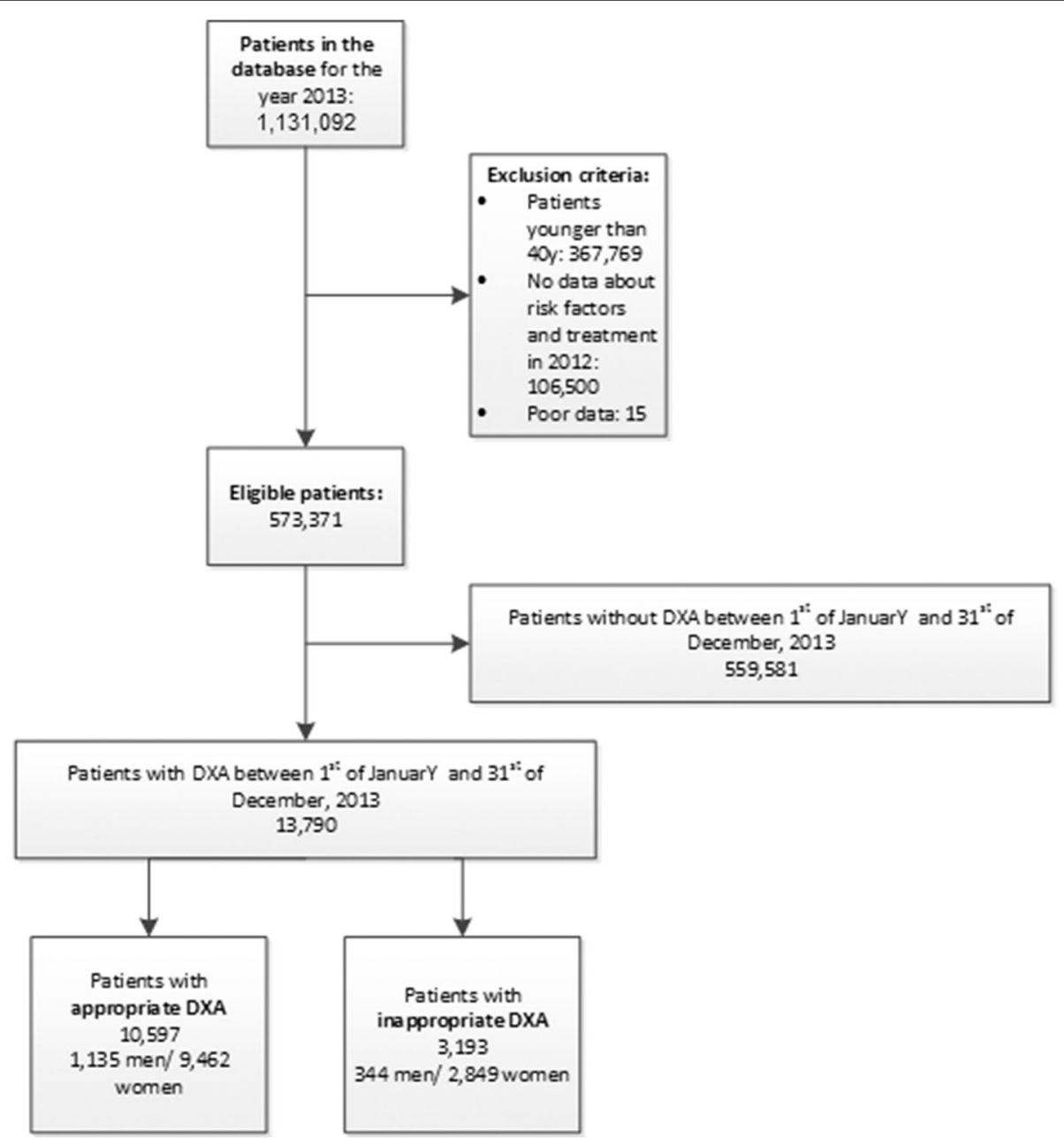

Fig. 1 Patient inclusion flowchart. This figure shows individual reasons why patients were excluded and the amount of patients finally included in the study 
b. Inpatient setting: Diagnosis Related Groups (DRG), International Classification of Diseases (ICD) and Swiss classification of operations (CHOP) for surgical interventions. An additional file shows this in more detail [see Additional file 1].

\section{Exclusion criteria}

- No data on area of living

- No data on risk factors and treatment of osteoporosis in 2012

- No data on treatment of osteoporosis in 2014

- Previous use of antiresorptive medication (in this condition DXA might be used for monitoring of treatment and not for screening purpose)

- Diagnosis of osteoporosis

- Age below 40 years

\section{Definition of osteoporosis and risk factors for osteoporosis}

Osteoporosis was defined by diagnostic code (ICD, DRG) or use of antiresorptive medication (ATC). Risk factors for osteoporosis were defined according to the FRAX $^{\circ}$ score [11] and according to recommendations of the Swiss Association against Osteoporosis (SVGO) [20] (Table 1).

An additional file shows this in more detail [see Additional file 1].

\section{Variables}

\section{Socio-demographic characteristics}

- Age

- Gender

- Chronic conditions: According to the pharmaceutical cost group (PCG) model by Huber et al. [21]. We additionally defined a minimum of three prescriptions per year as precondition for the following chronic conditions: acid related disorders, pain, psychological disorders (sleep disorder, depression) and rheumatological conditions.

- Area of living: Typology of Swiss communities defined by the Swiss Federal Statistical Office into 'urban' ('central city', 'isolated city', 'agglomeration'), and 'rural' ('rural areas') (data originates from

"Gemeindetypologie - Bundesamt für Statistik" 2003)

- Density of DXA facilities: The number of DXA facilities per canton was adjusted to the number of residents per canton and then categorized into four quartiles (data originates from "Bewilligungstatistik Bundesamt für Gesundheit” 2016)

\section{Socio-economic characteristics}

- Socio-economic status using income levels per corresponding zip code as a proxy [22]. Income level categorized into lowest 5\%, middle 90\%, and highest $5 \%$.

- Insurance Status:

- Supplementary private hospital insurance

- Deductibles $\geq$ or $<1000$ Swiss francs (CHF); High deductible class, e.g. 1000, 1500, 2000, or 2500 CHF as compared to the standard deductible of 300 or $500 \mathrm{CHF}$

- Managed care: We defined health plans with capitation, family doctor models, or telemedicine models as managed care models.

\section{Analysis}

First we calculated number and proportion of patients receiving any DXA screening. In a second step, number and proportion of patients receiving potentially inappropriate respectively appropriate DXA screening were calculated.

Table 1 Definitions of osteoporosis and risk factors of osteoporosis

\begin{tabular}{|c|c|c|}
\hline Characteristics & Coding System & Indicator \\
\hline Osteoporosis $^{a}$ & Using ICD, ATC codes & $\begin{array}{l}\text { Diagnostic code (ICD, DRG), antiresorptive } \\
\text { medication (ATC) }\end{array}$ \\
\hline $\begin{array}{l}\text { Risk factors for osteoporosis } \\
\text { according to FRAX }{ }^{\circledR} \text { score }^{a}[11]\end{array}$ & $\begin{array}{l}\text { Using ICD, DRG, CHOP, } \\
\text { Tarmed and ATC codes }\end{array}$ & $\begin{array}{l}\text { Steroid medication, fracture in typical } \\
\text { location (distal radius fracture, proximal } \\
\text { humerus fracture, vertebral fracture, femur } \\
\text { fracture) rheumatoid arthritis, insulin } \\
\text { dependent diabetes (as a proxy variable } \\
\text { for type I diabetes), osteogenesis imperfecta, } \\
\text { hyperthyroidism, hypogonadism, chronic liver } \\
\text { disease, nicotine and alcohol abuses, malnutrition, } \\
\text { underweight or malabsorption (including gastric } \\
\text { by-pass and inflammatory bowel disease) }\end{array}$ \\
\hline $\begin{array}{l}\text { Risk factors for osteoporosis } \\
\text { according to Swiss Association } \\
\text { against Osteoporosis (SVGO) }\end{array}$ & $\begin{array}{l}\text { Using ICD, DRG, CHOP, } \\
\text { Tarmed and ATC codes }\end{array}$ & $\begin{array}{l}\text { Hyperparathyroidism, hypothyroidism, asthma } \\
\text { or COPD, multiple myeloma, antiepileptic } \\
\text { drugs and anti-HIV drugs }\end{array}$ \\
\hline
\end{tabular}


Any DXA screening performed on women $<65$ and on men $<70$ years without any risk factors for osteoporosis was defined as potentially inappropriate. For presentation of results, data was categorized by 5 -year age strata, gender and existence of risk factors.

DXA screening performed on women $>65$ and on men $>70$ years or DXA screening performed on women $<65$ and on men $<70$ years with risk factors for osteoporosis was defined as appropriate DXA screening. For presentation, data was categorized by 5 -year age strata, gender and existence of risk factors.

Furthermore, we analyzed independent covariates for receiving any DXA screening as well as independent covariates for receiving potentially inappropriate DXA screening.

We used descriptive statistics to provide a general profile of the study population. For continuous variables, we used means with standard deviations (SD) or median and interquartile ranges (IQR), for categorical variables counts and percentages. We used Kruskal-Wallis, Fisher exact and Chi-Square tests as applicable to compare the group with and without any DXA, respectively. We categorized cases by gender and 5-year strata of age.

We performed multivariable regression analysis to estimate the effect of any of the covariates age, gender, health insurance coverage, region density of DXA facilities, income level, number of chronic conditions, risk factors and known osteoporosis on the patient's probability of having any DXA. In the model for the patient's probability of having a potentially inappropriate DXA, we included the covariates age, gender, health insurance coverage, region, income level, number of chronic conditions and density of DXA facilities. For these multivariable models, we used logistic regression.

\section{Results}

From our database consisting of 1,131,092 patients, 552,973 were finally included for analysis (See Fig. 1). The majority of patients was excluded due to age below 40 years $(365,511)$, missing data on risk factors and treatment of osteoporosis in 2012 (106,500), as well as due to missing data on treatment of osteoporosis in $2014(83,437)$.

Included patients had a median age of 60 (IQR 22.0) years, 292,377 (52.9\%) were female, 424,875 (76.8\%) were living in urban areas and had a median of 1 (IQR 3.0) chronic conditions (see Table 2).

\section{Proportion of patients with any DXA screening}

$10,000(1.8 \%)$ of all patients $(552,973)$ included in this study received any DXA screening. Median age of patients with any DXA screening was 66 (IQR 16.0) years, 8884 (88.8\%) were female, 8101 (81.0\%) lived in urban areas and had a median of 2 (IQR 3.0) chronic conditions. The age of patients with any DXA was significantly higher than the age of patients with no DXA (mean age 66.0 compared to 60.0). The proportion of female sex among patients with any DXA was significantly higher compared to those patients with no DXA (88.8\% vs. $52.2 \%)$. Also most other covariates differed significantly between patients with any DXA and patients without (see Table 2).

\section{Proportion of patients with potentially inappropriate DXA screening}

$2637(26.4 \%)$ of patients with DXA $(10,000)$ received a potentially inappropriate DXA screening. 2378 (90.2\%) were female and 259 (9.8\%) were male. By definition, only patients in the age groups $<65$ years in women and in the age groups $<70$ years in men were potentially affected (see Table 3).

\section{Independent covariates associated with any DXA screening}

The majority of investigated covariates were significantly $(p<0.002)$ associated with any DXA screening (see Fig. 2). Following covariates showed the greatest effect: Female sex (Odds ratio 6.47, CI 6.41-6.54), age group 70-74 (Odds ratio 6.23, CI 6.08-6.38), age group 65-69 (Odds ratio 6.19, CI 6.04-6.34), age group 75-79 (Odds ratio 5.18, CI 5.03-5.34), age group 55-59 (Odds ratio 5.04, CI 4.89-5.19) as well as the risk factors hypogonadism (Odds ratio 6.12, CI 6.02-6.22), history of fracture (Odds ratio 4.78, CI 4.62-4.94) and rheumatoid arthritis (Odds ratio 3.24, CI 3.13-3.35). Details see Fig. 2 and Additional file 2.

\section{Independent covariates associated with potentially inappropriate DXA screening}

Female sex (Odds ratio 1.84, CI 1.49-2.26), income level among the highest $5 \%$ (Odds ratio 1.40, CI 1.01-1.98), number of chronic conditions (Odds ratio 0.67, CI 0.65-0.70) and living in the central region of Switzerland (Odds ratio 0.67 , CI $0.48-0.95)$ were significantly $(p<0.05)$ associated with potentially inappropriate DXA screening. All other covariates were not significantly associated (Details see Fig. 3 and Additional file 3).

\section{Discussion}

In this cross-sectional study, 2637 patients $(26.4 \%$ of all 10,000 patients with any DXA screening) received a potentially inappropriate DXA. Female gender and income level among the highest 5\%, were significantly positively associated with potentially inappropriate DXA screening, number of chronic conditions and living in the central region of Switzerland negatively.

Overall 10,000 patients (1.8\% of our total study population) received any DXA screening, 8884 (3.0\%) of all women and $1116(0.4 \%)$ of all men in 2013. Previous 
Table 2 Demographic baseline data

\begin{tabular}{|c|c|c|c|c|c|}
\hline Covariates & Total & No DXA & Any DXA & $p$-Value & Test \\
\hline$n$ & 552,973 & $542,973(98.2 \%)$ & $10,000(1.8 \%)$ & & \\
\hline Age & $60.0(22.0)$ & $60.0(21.0)$ & $66.0(16.0)$ & $<2.2 \mathrm{e}-16^{* * *}$ & ' \\
\hline Female sex & $292,377(52.9 \%)$ & $283,493(52.2 \%)$ & $8884(88.8 \%)$ & $<2.2 \mathrm{e}-16^{* * *}$ & $"$ \\
\hline Managed care & $249,826(45.2 \%)$ & $245,628(45.2 \%)$ & $4198(42.0 \%)$ & $\begin{array}{l}8.52 \mathrm{e}-11 \\
* * *\end{array}$ & $"$ \\
\hline Deductible $\geq$ CHF 1000 & $143,295(25.9 \%)$ & $142,212(26.2 \%)$ & $1083(10.8 \%)$ & $<2.2 \mathrm{e}-16^{* * *}$ & $"$ \\
\hline Supplementary hospital insurance & $127,080(23.0 \%)$ & $123,689(22.8 \%)$ & 3391 (33.9\%) & $<2.2 \mathrm{e}-16^{* * *}$ & $"$ \\
\hline Region & & & & $<2.2 \mathrm{e}-16^{* * *}$ & un \\
\hline Midland & $110,347(20.0 \%)$ & $108,473(20.0 \%)$ & $1874(18.7 \%)$ & & \\
\hline Northwest & $76,568(13.8 \%)$ & $75,141(13.8 \%)$ & $1427(14.3 \%)$ & & \\
\hline East & $78,285(14.2 \%)$ & $76,914(14.2 \%)$ & $1371(13.7 \%)$ & & \\
\hline Lake Geneva & $70,177(12.7 \%)$ & $68,800(12.7 \%)$ & $1377(13.8 \%)$ & & \\
\hline Ticino & $40,729(7.4 \%)$ & $39,915(7.4 \%)$ & $814(8.1 \%)$ & & \\
\hline Central & $48,871(8.8 \%)$ & $48,225(8.9 \%)$ & $646(6.5 \%)$ & & \\
\hline Zurich & $127,996(23.1 \%)$ & $125,505(23.1 \%)$ & $2491(24.9 \%)$ & & \\
\hline Urban area & $424,875(76.8 \%)$ & $416,774(76.8 \%)$ & $8101(81.0 \%)$ & $\underset{* * *}{<2.2 \mathrm{e}-16}$ & $"$ \\
\hline Density DXA facilities & & & & $3.18 \mathrm{e}-13 * * *$ & un \\
\hline 1. quartile & $146,876(26.6 \%)$ & $144,549(26.6 \%)$ & $2327(23.3 \%)$ & & \\
\hline 2. quartile & $158,878(28.7 \%)$ & $155,932(28.7 \%)$ & $2946(29.5 \%)$ & & \\
\hline 3. quartile & $156,620(28.3 \%)$ & $153,514(28.3 \%)$ & $3106(31.1 \%)$ & & \\
\hline 4. quartile & $90,599(16.4 \%)$ & $88,978(16.4 \%)$ & $1621(16.2 \%)$ & & \\
\hline Purchasing power & & & & $3.39 \mathrm{e}-07^{* * *}$ & un \\
\hline middle & $498,052(90.1 \%)$ & $489,136(90.1 \%)$ & $8916(89.2 \%)$ & & \\
\hline lowest & $28,221(5.1 \%)$ & $27,744(5.1 \%)$ & $477(4.8 \%)$ & & \\
\hline highest & $26,700(4.8 \%)$ & $26,093(4.8 \%)$ & $607(6.1 \%)$ & & \\
\hline Use of antidepressive drugs & $59,602(10.8 \%)$ & $57,984(10.7 \%)$ & $1618(16.2 \%)$ & $<2.2 \mathrm{e}-16^{* * *}$ & $"$ \\
\hline Risk factor: History of fracture & $1874(0.3 \%)$ & $1673(0.3 \%)$ & $201(2.0 \%)$ & $<2.2 \mathrm{e}-16^{* * *}$ & $"$ \\
\hline Risk factor: Osteogenesis imperfecta & $1(0.0 \%)$ & $1(0.0 \%)$ & $0(0.0 \%)$ & 1 & $"$ \\
\hline Risk factor: Hypogonadism & $3562(0.6 \%)$ & $2989(0.6 \%)$ & $573(5.7 \%)$ & $<2.2 \mathrm{e}-16^{* * *}$ & “ \\
\hline Risk factor (SVGO): Hyperparathyroidism & $341(0.1 \%)$ & $317(0.1 \%)$ & $24(0.2 \%)$ & $2.53 e-08 * * *$ & $"$ \\
\hline Risk factor: Hyperthyroidism & $1171(0.2 \%)$ & $1136(0.2 \%)$ & $35(0.4 \%)$ & $0.005611 * *$ & $"$ \\
\hline Risk factor (SVGO): Hypothyroidism & $25,595(4.6 \%)$ & $24,621(4.5 \%)$ & $974(9.7 \%)$ & $<2.2 \mathrm{e}-16^{* * *}$ & $"$ \\
\hline Risk factor: Malnutrition & $2270(0.4 \%)$ & $2207(0.4 \%)$ & $63(0.6 \%)$ & $0.001148 * *$ & $"$ \\
\hline Risk factor: Steroid therapy & $45,443(8.2 \%)$ & $43,206(8.0 \%)$ & $2237(22.4 \%)$ & $<2.2 \mathrm{e}-16^{* * *}$ & $"$ \\
\hline Risk factor: Inflammatory bowel disease & $4291(0.8 \%)$ & $3990(0.7 \%)$ & $301(3.0 \%)$ & $<2.2 \mathrm{e}-16^{* * *}$ & $"$ \\
\hline Risk factor: Rheumatoid arthritis & $4900(0.9 \%)$ & $4401(0.8 \%)$ & $499(5.0 \%)$ & $<2.2 \mathrm{e}-16^{* * *}$ & " \\
\hline Risk factor: Insulin dependent diabetes & $11,399(2.1 \%)$ & $11,210(2.1 \%)$ & 189 (1.9\%) & 0.241 & $"$ \\
\hline Risk factor: Chronic liver disease & $507(0.1 \%)$ & $489(0.1 \%)$ & $18(0.2 \%)$ & $0.006869 * *$ & $"$ \\
\hline Risk factor: Nicotine abuse & $893(0.2 \%)$ & $871(0.2 \%)$ & $22(0.2 \%)$ & 0.1641 & $"$ \\
\hline Risk factor: Alcohol abuse & $1435(0.3 \%)$ & $1400(0.3 \%)$ & $35(0.4 \%)$ & 0.07417 & “ \\
\hline Risk factor (SVGO): Emerging risk factors & $38,633(7.0 \%)$ & $37,539(6.9 \%)$ & $1094(10.9 \%)$ & $<2.2 \mathrm{e}-16^{* * *}$ & $"$ \\
\hline Number of chronic conditions & $1.0(3.0)$ & $1.0(3.0)$ & $2.0(3.0)$ & $<2.2 \mathrm{e}-16^{* * *}$ & $'$ \\
\hline
\end{tabular}

Number and proportion of covariates of patients with any DXA screening and with no DXA screening respectively. Abbreviations: "Total" = all included patients, "Any DXA" = all patients who received any DXA screening, "No DXA" = all patients receiving no DXA screening. Significance levels are marked accordingly: *** $\leq$ $0.001,{ }^{* *}=0.001-0.01,{ }^{*}=0.01-0.05$, empty $=0.05-1 .{ }^{\prime}=$ Kruskal-Wallis test, ${ }^{\prime \prime}=$ Fisher exact test, ${ }^{\prime \prime \prime}=$ Chi-Square test 
Table 3 Appropriateness of DXA

\begin{tabular}{|c|c|c|c|c|c|c|}
\hline & \multicolumn{3}{|l|}{ Men } & \multicolumn{3}{|l|}{ Women } \\
\hline & $\begin{array}{l}n \text { of patients with } \\
\text { DXA without risk } \\
\text { factor }\end{array}$ & $\begin{array}{l}\mathrm{n} \text { of patients with } \\
\text { DXA with } \geq 1 \text { risk } \\
\text { factor }\end{array}$ & $\begin{array}{l}\mathrm{N} \text { of patients } \\
\text { in the sample }\end{array}$ & $\begin{array}{l}n \text { of patients with } \\
\text { DXA without risk } \\
\text { factor }\end{array}$ & $\begin{array}{l}n \text { of patients with } \\
\text { DXA with } \geq 1 \text { risk } \\
\text { factor }\end{array}$ & $\begin{array}{l}\mathrm{N} \text { of patients } \\
\text { in the sample }\end{array}$ \\
\hline $40-44$ & 16 & 24 & 32,081 & 95 & 70 & 31,480 \\
\hline $45-49$ & 27 & 50 & 35,421 & 206 & 168 & 34,998 \\
\hline $50-54$ & 39 & 67 & 34,311 & 471 & 296 & 34,558 \\
\hline $55-59$ & 40 & 85 & 31,922 & 715 & 443 & 32,743 \\
\hline $60-64$ & 62 & 70 & 30,005 & 891 & 548 & 32,141 \\
\hline $65-69$ & 75 & 109 & 29,949 & 919 & 652 & 32,112 \\
\hline $70-74$ & 78 & 103 & 24,421 & 774 & 651 & 28,148 \\
\hline $75-79$ & 44 & 85 & 18,927 & 534 & 530 & 24,150 \\
\hline $80-84$ & 44 & 58 & 13,477 & 327 & 313 & 20,360 \\
\hline $85-89$ & 19 & 15 & 7124 & 120 & 122 & 13,878 \\
\hline$\geq 90$ & 2 & 4 & 2958 & 19 & 20 & 7809 \\
\hline Sum & 446 & 670 & 260,596 & 5071 & 3813 & 292,377 \\
\hline
\end{tabular}

Number of patients with potentially inappropriate respectively appropriate DXA screening stratified by 5 -year strata of age and sex

studies found higher proportions of patients with any DXA, e.g. $20 \%$ for women and 3 to $4 \%$ for men $[13,23$, 24]. Comparisons between these studies seem difficult due to differences in populations, settings and time periods. Female gender, age and the majority of established risk factors for osteoporosis were significantly associated with any DXA screening, corresponding with the literature $[13,18,23,25,26]$. This finding confirms that the set of covariates chosen in our study is valid for discriminating between patients at risk for osteoporosis and patients not at risk.

In contrast to our finding that $26.8 \%$ of all women and $23.2 \%$ of all men received a potentially inappropriate DXA, previous studies reported 10 to $20 \%$ of inappropriate DXA

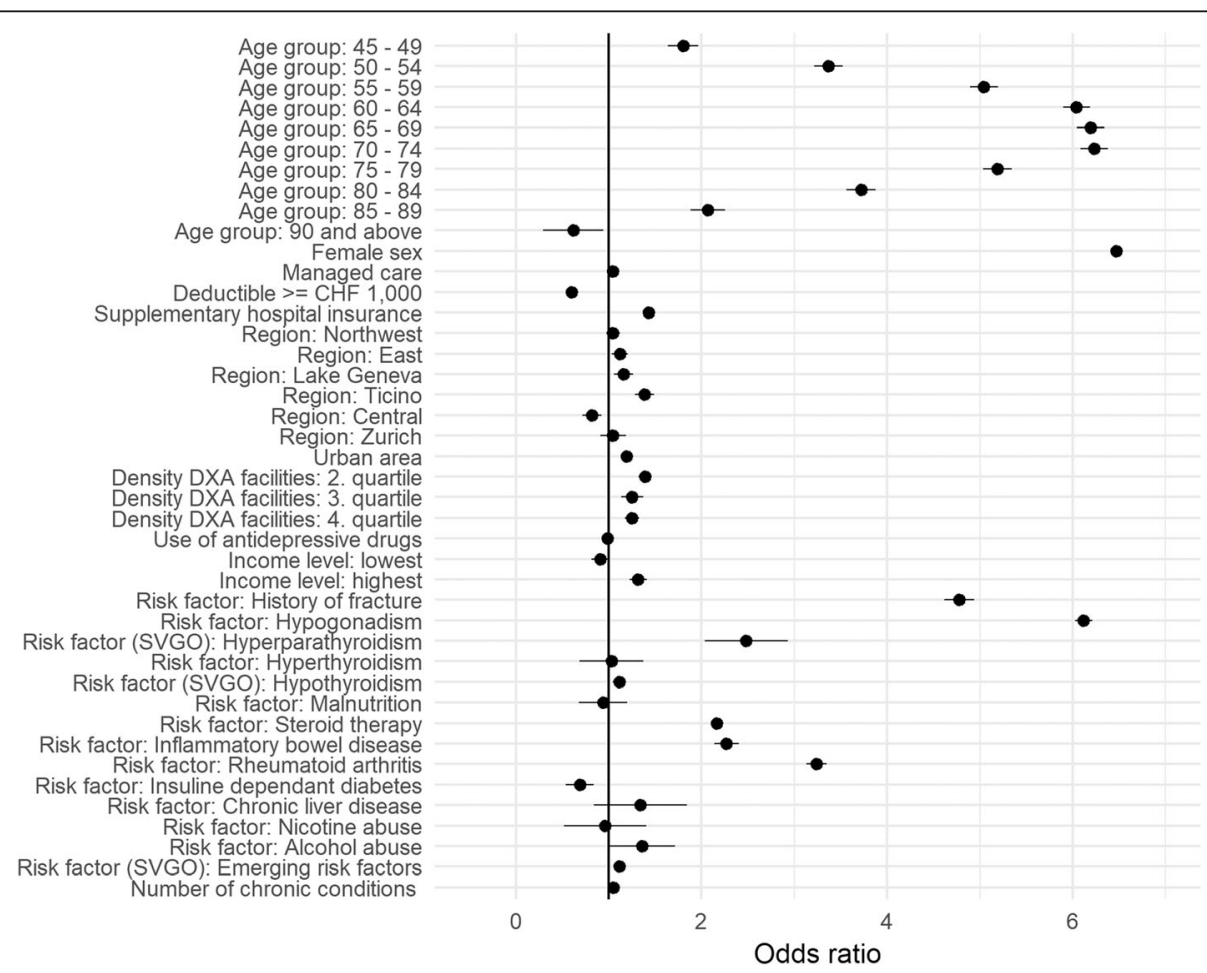

Fig. 2 Multivariable model of any DXA. Multivariable analysis of socio-demographic, socio-economic and clinical covariates of patients receiving any DXA 


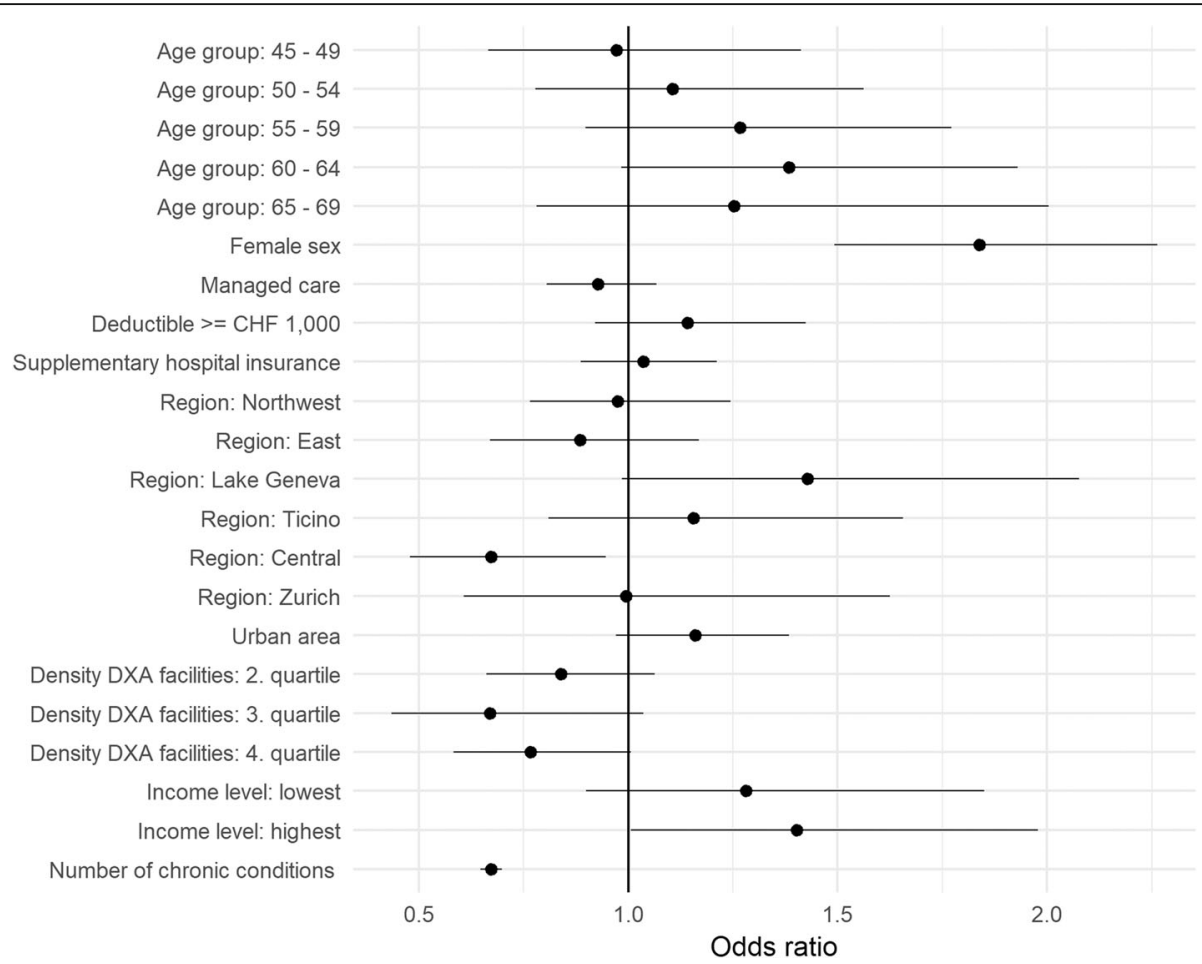

Fig. 3 Multivariable model of potentially inappropriate DXA. Multivariable analysis of age, gender, socio-demographic, socio-economic and clinical covariates of patients receiving a potentially inappropriate DXA

among women and $16 \%$ among men [16]. Frost et al. found that one out of three patients with DXA did not have any risk factor for osteoporosis, while one out of five patients with DXA did not have any risk factor when family history and falls are included [18].

The number of potentially inappropriate DXA increased continuously until the age of 65 years (e.g. almost doubling with the age of 60-65 compared to 50-55). Female gender and a higher age are the two risk factors best known to patients [27]. This specific subgroup might ask more actively for DXA screening due to their higher risk awareness. This might be a result of public campaigns successfully fostering awareness of osteoporosis among this specific subgroup, at least in high-income countries like Switzerland [28]. Unfortunately, most public campaigns fail to provide information on inappropriate DXA screening indications (e.g. younger age). Gender differences in screening programs in general, as well as in osteoporosis screening programs, have been observed before [29-35]. Besides inherent gender differences, lack of campaigns promoting health specifically for men might be a major contributor to this finding $[36,37]$. Amarnath et al. argue that some physicians still use DXA as a screening tool for all menopausal women regardless of age or other risk factors [13].

An income level among the highest $5 \%$ was significantly associated with inappropriate DXA screening as well. A higher level of income might be a proxy for higher education [25]. Health campaigns usually reach higher educated people rather than lower educated, leading to a higher risk awareness and resulting in higher demand for screening among this subgroup. Amarnath et al. found underuse of other screening procedures in patients with lower education level, confirming our finding [13].

The number of chronic conditions commonly used as a proxy for an elderly, multimorbid population was significantly negatively associated with a potentially inappropriate DXA screening. As multimorbidity is associated with age and frailty, this population is more prone to osteoporosis, and thus more frequently and more appropriately transferred to DXA screening.

Variations between regions might be due to differences in needs and attitudes of patients or physicians living in these regions. Furthermore, differences in physician density and therefore unequal access to medical supply could be an additional reason. Born et al. reported similar findings for the central and Lake Geneva region of Switzerland as well [25].

Living in a canton with a higher density of DXA facilities led to a higher proportion of any DXA screening. Rubin et al similarly reported a higher density of DXA facilities as a trigger for a higher use of DXA [16]. This findings undermined the economic model that higher supply is likely to trigger higher demand [38]. Remarkably, there was no significant association between a higher density of DXA facilities and potentially 
inappropriate DXA, therefore not directly contributing to overuse.

We found a significant positive association with a deductible $\geq 1000 \mathrm{CHF}$ and supplementary hospital insurance with any DXA. However, there was no significant association of these covariates with potentially inappropriate DXA. As discussed above a supplementary hospital insurance is a possible proxy for a higher income level and thus a higher education leading to a higher demand for DXA screening $[25,39]$.

Finally, overuse of DXA may be triggered by physicians' and patients' belief that the potential benefit of DXA is weighing out its minimal risk of harm, even in the absence of risk factors for osteoporosis, regardless of the risk of overdiagnosis and overtreatment [13, 40, 41].

\section{Strengths}

A major strength of this study is the large and representative sample size (14\% of the Swiss population). Many studies investigating proportions and covariates of DXA screening were based on smaller samples [16, 18, 25, 42].

We focused on DXA for screening intentions only, while most studies did not differentiate between reasons for performing DXA (screening, diagnosis, or monitoring of medical treatment). Hence, we were able to avoid misclassification bias concerning the indication for a DXA.

We tested a set of clinically reasonable covariates, which reasonability was confirmed by the findings of our regression analysis on covariates.

\section{Limitations}

In our database, important risk factors such as family or patient history were not available (a limitation which a majority of comparable studies had to face as well). These circumstances might have led to some misclassification bias. Frost et al. reported that $10.3 \%$ and $15.1 \%$ of all patients receiving a DXA had a family history of hip fracture and family history of osteoporosis respectively.

The use of data of 1 year (2013) only restricts the comparability to other studies and is therefore a limitation.

\section{Further research and recommendations}

Attitudes and beliefs concerning DXA screening among healthcare providers as well as patients might be interesting aspects to explore by qualitative or mixed methods research. The results of this research might facilitate implementation of more appropriate DXA screening.

As discussed above, further initiatives and campaigns should not only foster awareness, but should also focus on correct information transfer concerning screening indication and benefits.
Additionally a two-step screening process consisting of risk assessment using cost-effective validated tools followed by DXA could be beneficial [43-46].

\section{Conclusion}

One out of four DXAs for screening purpose is potentially inappropriate. Stakeholders of osteoporosis screening campaigns should focus on providing more detailed information on appropriateness of DXA screening indications (e.g. age thresholds) in order to avoid DXA overuse.

\section{Additional files}

Additional file 1: "Definition of variables". In this file you can see in detail which coding was used for diagnosis and risk factors. (PDF $76 \mathrm{~kb}$ )

Additional file 2: "Multivariable model of any DXA". In this file we present the same data as presented in Fig. 2 (multivariable analysis of socio-demographic, socio-economic and clinical covariates in patients with any DXA), but in tabular form including estimate (Odds ratio), confidence intervals and $p$-value. Significance levels are marked accordingly: ${ }^{* *} \leq 0.001,{ }^{* *}=0.001-0.01,{ }^{*}=0.01-0.05$, empty $=0.05-1$ (XLS $31 \mathrm{~kb}$ )

Additional file 3: "Multivariable model of potentially inappropriate DXA". In this file we present the same data as presented in Fig. 2 (multivariable analysis of age, sex, socio-demographic, socio-economic and clinical covariates in patients with a potentially inappropriate DXA), but in tabular form including estimate (Odds ratio), confidence intervals and p-value. Significance levels are marked accordingly: ${ }^{* *} \leq 0.001,{ }^{* *}=0.001-0.01$, * $=0.01-0.05$, empty $=0.05-1 .($ XLS $29 \mathrm{~kb})$

\section{Abbreviations}

ATC: Anatomical Therapeutic Chemical (Classification System for drugs); CHF: Swiss francs; CHOP: Swiss classification of operations; DRG: Diagnosis Related Groups; DXA: Dual X-ray Absorptiometry; ICD: International Classification of Diseases; IQR: Interquartile range; PCG: Pharmaceutical cost group; SD: Standard deviations; SVGO: Swiss Association against Osteoporosis; Tarmed: Outpatient care fees-for-services positions

\section{Acknowledgements}

Not applicable.

\section{Funding}

This work was funded by the Gottfried und Julia Bangerter-Rhyner-Stifung, Basel. Helsana Group provided support in the form of salaries for OR and BB. The funders had no role in the study design, data collection and analysis, decision to publish, or preparation of the manuscript.

\section{Availability of data and materials}

The data that support the findings of this study are available from Helsana but restrictions apply to the availability of these data, which were used under license for the current study, and so are not publicly available. Data are however available from the authors upon reasonable request and with permission of Helsana.

\section{Authors' contributions}

Conceived and designed the analysis: SZ, NS, OR, BB, OS, TR, SNJ. Performed the analysis: BB, OR. Analyzed and interpreted the data: SZ, NS, OR, BB, OS, TR, SNJ. Drafted the manuscript: SZ, NS, SNJ. Read and approved the final manuscript: SZ, NS, OR, BB, OS, TR, SNJ.

\section{Ethics approval and consent to participate}

In compliance with the Swiss Federal Law on data protection, all data were anonymized and de-identified to protect the privacy of patients, physicians and hospitals. As data were routinely collected, retrospective, pre-existing, 
and de-identified, no informed consent of patients was required and the study was exempted from ethics committee approval in accordance to the Swiss law on human research [47].

\section{Consent for publication}

Not applicable.

\section{Competing interests}

$\mathrm{SZ}, \mathrm{NS}, \mathrm{OR}, \mathrm{BB}, \mathrm{OS}$, TR and SNJ declare that they have no competing interests or financial disclosures.

\section{Publisher's Note}

Springer Nature remains neutral with regard to jurisdictional claims in published maps and institutional affiliations.

\section{Author details}

${ }^{1}$ Institute of Primary Care, University of Zurich, Pestalozzistrasse 24, 8091 Zurich, Switzerland. ${ }^{2}$ Department of Health Sciences, Helsana Group, Zurich, Switzerland.

\section{Received: 11 October 2017 Accepted: 13 March 2018}

\section{Published online: 02 April 2018}

\section{References}

1. Global status report on noncommunicable diseases 2014. World health organisation; Available from: http://www.who.int/nmh/publications/ncdstatus-report-2014/en/. Accessed 20 Mar 2018.

2. Svedbom A, Hernlund E, Ivergard M, Compston J, Cooper C, Stenmark J, McCloskey EV, Jonsson B, Kanis JA, IOF EURPo. Osteoporosis in the European Union: a compendium of country-specific reports. Arch Osteoporos. 2013;8:137.

3. Mohd-Tahir NA, Li SC: Economic burden of osteoporosis-related hip fracture in Asia: a systematic review. Osteoporos Int. 2017;28(7):2035-44.

4. Darba J, Kaskens L, Perez-Alvarez N, Palacios S, Neyro JL, Rejas J. Disabilityadjusted-life-years losses in postmenopausal women with osteoporosis: a burden of illness study. BMC Public Health. 2015:15:324

5. Gauthier A, Kanis JA, Jiang Y, Dreinhofer K, Martin M, Compston J, Borgstrom F, Cooper C, McCloskey E. Burden of postmenopausal osteoporosis in Germany: estimations from a disease model. Arch Osteoporos. 2012;7:209-18.

6. Lippuner K, Johansson H, Kanis JA, Rizzoli R. Remaining lifetime and absolute 10-year probabilities of osteoporotic fracture in Swiss men and women. Osteoporos Int. 2009;20(7):1131-40.

7. Cosman F, de Beur SJ, LeBoff MS, Lewiecki EM, Tanner B, Randall S, Lindsay $R$, National Osteoporosis F. Clinician's guide to prevention and treatment of osteoporosis. Osteoporos Int. 2014;25(10):2359-81.

8. Schwenkglenks M, Lippuner K. Simulation-based cost-utility analysis of population screening-based alendronate use in Switzerland. Osteoporos Int. 2007:18(11):1481-91.

9. Watts NB, Adler RA, Bilezikian JP, Drake MT, Eastell R, Orwoll ES, Finkelstein JS, Endocrine S. Osteoporosis in men: an Endocrine Society clinical practice guideline. J Clin Endocrinol Metab. 2012;97(6):1802-22.

10. Kanis JA, Hans D, Cooper C, Baim S, Bilezikian JP, Binkley N, Cauley JA, Compston JE, Dawson-Hughes B, El-Hajj Fuleihan G, et al. Interpretation and use of FRAX in clinical practice. Osteoporos Int. 2011;22(9):2395-411.

11. FRAX ${ }^{\oplus}$ - Fracture Risk Assessment Tool; WHO - World Health Organisation: Collaborating Centre for Metabolic Bone Diseases UoS, UK; Available from: https://www.shef.ac.uk/FRAX/tool.aspx?lang=en. Accessed 20 Mar 2018.

12. Hoiberg MP, Rubin KH, Hermann AP, Brixen K, Abrahamsen B. Diagnostic devices for osteoporosis in the general population: a systematic review. Bone. 2016;92:58-69.

13. Amarnath $A L$, Franks $P$, Robbins JA, Xing G, Fenton JJ. Underuse and overuse of osteoporosis screening in a regional health system: a retrospective cohort study. J Gen Intern Med. 2015;30(12):1733-40.

14. Hurtado I, Sanfelix-Gimeno G, Baixauli-Perez C, Peiro S, Sanfelix-Genoves J. Impact on the population of different bone mineral density testing criteria and appropriateness of densitometries in the ESOSVAL cohort, Spain. J Clin Endocrinol Metab. 2014;99(1):142-50.

15. Kale MS, Bishop TF, Federman AD, Keyhani S. "Top 5" lists top \$5 billion. Arch Intern Med. 2011;171(20):1856-8.
16. Rubin KH, Abrahamsen B, Hermann AP, Bech M, Gram J, Brixen K. Prevalence of risk factors for fractures and use of DXA scanning in Danish women. A regional population-based study. Osteoporos Int. 2011; 22(5):1401-9.

17. Schnatz PF, Marakovits KA, Dubois M, O'Sullivan DM. Osteoporosis screening and treatment guidelines: are they being followed? Menopause. 2011; 18(10):1072-8.

18. Frost M, Gudex C, Rubin KH, Brixen K, Abrahamsen B. Pattern of use of DXA scans in men: a cross-sectional, population-based study. Osteoporos Int. 2012;23(1):183-91.

19. Jarvinen $T L$, Michaelsson $K$, Aspenberg P, Sievanen H. Osteoporosis: the emperor has no clothes. J Intern Med. 2015;277(6):662-73.

20. Osteoporose Empfehlungen 2015 - SVGO - Schweizerische Vereinigung gegen Osteoporose; Available from: http://www.svgo.ch/content/ documents/2015/SVGO\%20Empfehlungen\%202015.pdf. Accessed 20 Mar 2018

21. Huber CA, Szucs TD, Rapold R, Reich O. Identifying patients with chronic conditions using pharmacy data in Switzerland: an updated mapping approach to the classification of medications. BMC Public Health. 2013;13:1030.

22. GfK releases 2016 purchasing power for Austria and Switzerland. Available from: http://www.gfk.com/insights/press-release/pp-dach/. Accessed 20 Mar 2018.

23. Hoiberg MP, Rubin KH, Gram J, Hermann AP, Brixen K, Haugeberg G. Risk factors for osteoporosis and factors related to the use of DXA in Norway. Arch Osteoporos. 2015;10:16

24. Schwartz AV, Vittinghoff E, Bauer DC, Hillier TA, Strotmeyer ES, Ensrud KE, Donaldson MG, Cauley JA, Harris TB, Koster A, et al. Association of BMD and FRAX score with risk of fracture in older adults with type 2 diabetes. JAMA. 2011;305(21):2184-92.

25. Born R, Zwahlen M. Disparities in bone density measurement history and osteoporosis medication utilisation in Swiss women: results from the Swiss health survey 2007. BMC Musculoskelet Disord. 2013;14:10.

26. Brennan SL, Wluka AE, Gould H, Nicholson GC, Leslie WD, Ebeling PR, Oldenburg B, Kotowicz MA, Pasco JA. Social determinants of bone densitometry uptake for osteoporosis risk in patients aged 50yr and older: a systematic review. J Clin Densitom. 2012;15(2):165-75.

27. Ni Chroinin D, Glavin P, Power D. Awareness of osteoporosis, risk and protective factors and own diagnostic status: a cross-sectional study. Arch Osteoporos. 2013:8:117.

28. Langer FW, da Silveira Codevilla AA, Bringhenti R, Dal Osto LC, Campos TR, Martins TT, Barin AE, Rigo PH, Boufleuer ND, Santinon SF, et al. Low selfawareness of osteoporosis and fracture risk among postmenopausal women. Arch Osteoporos. 2016;11(1):27.

29. Wong RK, Wong ML, Chan YH, Feng Z, Wai CT, Yeoh KG. Gender differences in predictors of colorectal cancer screening uptake: a national cross sectional study based on the health belief model. BMC Public Health. 2013:13:677.

30. Klabunde C, Blom J, Bulliard JL, Garcia M, Hagoel L, Mai V, Patnick J, Rozjabek H, Senore C, Tornberg S. Participation rates for organized colorectal cancer screening programmes: an international comparison. J Med Screen. 2015:22(3):119-26.

31. Miranda-Diaz C, Betancourt E, Ruiz-Candelaria Y, Hunter-Mellado RF. Barriers for compliance to breast, colorectal, and cervical screening Cancer tests among Hispanic patients. Int J Environ Res Public Health. 2015;13(1): ijerph13010021.

32. Adler RA. The need for increasing awareness of osteoporosis in men. Clin Cornerstone. 2006:8(Suppl 3):S7-13.

33. Alswat K, Adler SM. Gender differences in osteoporosis screening: retrospective analysis. Arch Osteoporos. 2012;7:311-3.

34. Thompson L, Reeder T, Abel G. I can't get my husband to go and have a colonoscopy: gender and screening for colorectal cancer. Health (London) 2012:16(3):235-49

35. Weinstock MA, Martin RA, Risica PM, Berwick M, Lasater T, Rakowski W, Goldstein MG, Dube CE. Thorough skin examination for the early detection of melanoma. Am J Prev Med. 1999;17(3):169-75.

36. Katz ML, Sheridan S, Pignone M, Lewis C, Battle J, Gollop C, O'Malley M. Prostate and colon cancer screening messages in popular magazines. J Gen Intern Med. 2004:19(8):843-8.

37. Stryker JE, Emmons KM, Viswanath K. Uncovering differences across the cancer control continuum: a comparison of ethnic and mainstream cancer newspaper stories. Prev Med. 2007;44(1):20-5 
38. Theil H. Principles of Econometrics. Wiley. 1971, p. 768. ISBN: 978-0-47185845-4.

39. Overman RA, Farley JF, Curtis JR, Zhang J, Gourlay ML, Deal CL. DXA utilization between 2006 and 2012 in commercially insured younger postmenopausal women. J Clin Densitom. 2015;18(2):145-9.

40. Lipitz-Snyderman A, Bach PB. Overuse of health care services: when less is more ... More or less. JAMA Intern Med. 2013;173(14):1277-8.

41. Kravitz RL, Bell RA, Azari R, Krupat E, Kelly-Reif S, Thom D. Request fulfillment in office practice: antecedents and relationship to outcomes. Med Care. 2002;40(1):38-51.

42. Sanders KM, Nicholson GC, Watts JJ, Pasco JA, Henry MJ, Kotowicz MA Seeman $E$. Half the burden of fragility fractures in the community occur in women without osteoporosis. When is fracture prevention cost-effective? Bone. 2006;38(5):694-700.

43. McCloskey EV, Johansson H, Harvey NC, Compston J, Kanis JA. Access to fracture risk assessment by FRAX and linked National Osteoporosis Guideline Group (NOGG) guidance in the UK-an analysis of anonymous website activity. Osteoporos Int. 2017;28(1):71-6.

44. Kanis JA, Johansson H, Oden A, Cooper C, McCloskey EV. Worldwide uptake of FRAX. Arch Osteoporos. 2014;9:166.

45. Lippuner K, Johansson H, Borgstrom F, Kanis JA, Rizzoli R. Cost-effective intervention thresholds against osteoporotic fractures based on FRAX(R) in Switzerland. Osteoporos Int. 2012;23(11):2579-89.

46. Shepstone L, Lenaghan E, Cooper C, Clarke S, Fong-Soe-Khioe R, Fordham R, Gittoes N, Harvey I, Harvey N, Heawood A et al: Screening in the community to reduce fractures in older women (SCOOP): a randomised controlled trial. Lancet. 2018;391(10122):741-7.

47. Schweizer Bundesgesetz über die Forschung am Menschen 2011; Available from: https://www.admin.ch/opc/de/classified-compilation/20061313/index. html. Accessed 20 Mar 2018.

\section{Submit your next manuscript to BioMed Central and we will help you at every step:}

- We accept pre-submission inquiries

- Our selector tool helps you to find the most relevant journal

- We provide round the clock customer support

- Convenient online submission

- Thorough peer review

- Inclusion in PubMed and all major indexing services

- Maximum visibility for your research

Submit your manuscript at www.biomedcentral.com/submit

C) Biomed Central 